\title{
CDK Inhibitor AT7519
}

National Cancer Institute

\section{Source}

National Cancer Institute. CDK Inhibitor AT7519. NCI Thesaurus. Code C64761.

An orally bioavailable small molecule with potential antineoplastic activity. AT7519M

selectively binds to and inhibits cyclin dependent kinases (CDKs), which may result in cell

cycle arrest, induction of apoptosis, and inhibition of tumor cell proliferation. CDKs are

serine/threonine kinases involved in regulation of the cell cycle and may be

overexpressed in some types of cancer cells. 